\title{
La metáfora de la búsqueda: análisis de la metaforización kinésica en dos narraciones orales en gallego y portugués
}

\author{
Aitor Rivas*
}

\begin{abstract}
Resumen
Muchos investigadores, partiendo de las ideas de Hall (1959, 1968), mantienen que el $60 \%$ de la comunicación personal es absolutamente no verbal, creyendo asimismo que es mucho más importante lo que transmitimos con nuestros gestos que lo que expresamos verbalmente. $\mathrm{Mi}$ corpus de estudio para este trabajo está conformado por la grabación de dos narraciones orales de hablantes nativas de gallego y portugués de Brasil. En este artículo pretendo analizar la intervención de la comunicación no verbal en los procedimientos de metaforización kinésica para transmitir y representar metáforas en esos relatos orales. La metodología de trabajo está basada en las propuestas de análisis de comunicación no verbal formuladas por Birdwhistell (1952, 1970), Poyatos (1994a, 1994b), Bouvet (2001) y Galhano Rodrigues (2007). Después del análisis se puede observar la alta capacidad metafórica de los procedimientos kinésicos.
\end{abstract}

Palabras-clave: Metaforización. Kinésica. No verbal. Oralidad. Búsqueda.

\section{Introducción}

La intención primera de este trabajo es exponer cuáles son las relaciones que se establecen entre las metáforas y los gestos. A través del análisis de algunos fragmentos de las grabaciones en vídeo de dos narrativas personales quiero mostrar los procedimientos de creación de algunas metáforas gestuales y cómo interviene la kinésica en esas narraciones.

Partiendo de la concepción de la estructura triple básica de la comunicación humana — lenguaje, paralenguaje y kinésica - propuesta por Poyatos (1994a, 1994b) y de la experiencia de análisis de Birdwhistell (1970), pretendo acercarme

* Es licenciado en Filología Gallega y tiene un Máster en Contacto Lingüístico y Sociolingüística Gallega en la Universidade de Vigo (Galicia). Trabajó como profesor de lenguas en centros de educación secundaria y fue lector de Gallego en la Eberhard Karls Universität de Tübingen (Alemania) y profesor-lector de Español en la Universidade Federal de Viçosa (UFV, Brasil). E-mail: aitorrivas@ gmail.com 
a dos temas que se complementan en la narración: la kinésica (pilar importantísimo de la comunicación no verbal) y su función creadora y transmisora de metáforas en el transcurso de una narración oral. Probablemente esta capacidad metafórica de la kinésica sea uno de los fenómenos más interesantes de la comunicación no verbal.

Según Torralba (2006), "el gesto es físico, es tangible, es vivencial y directo", lo que significa que se puede percibir directamente y que tiene mayor poder de atracción y visualización que la palabra. Por eso me parece importante la relación que se establece entre los gestos y las metáforas, un tema objeto de estudio de numerosos trabajos.

A modo de ejemplo, Cienki y Müller (2008) comprobaron que el gesto revela y transmite esquemas metafóricos presentes en otros ámbitos. En este artículo voy a aislar y comentar algunos gestos metafóricos. Los gestos metafóricos se pueden definir como un conjunto de kinemas que contribuyen a la creación de una imagen de algo abstracto, es decir, dibujan objetos a los que se pueden atribuir significados abstractos. Estos gestos pueden subrayar, reforzar y, algunas veces, también contradecir las palabras del discurso verbal. Por eso los procedimientos de metaforización kinésica (que atraen nuevos significados y recogen otros existentes) son de suma importancia en el análisis de la comunicación oral.

\section{El corpus para el análisis}

Mi corpus para este trabajo está formado por dos grabaciones de narraciones orales de dos hablantes nativas de gallego y de portugués de Brasil. Siguiendo las recomendaciones ofrecidas por Duranti (2000), hice las grabaciones en vídeo de las historias, actuando con la máxima naturalidad posible e intentando no interferir en ninguna de las dos narraciones.

Previamente había hablado con las narradoras y les pedí colaboración para que contasen una historia graciosa que habían vivido o que le había pasado a algún amigo o amiga, para centrar su atención en la historia y no en las formas. Sólo sabían que tendrían que contar una historia personal con algún aspecto gracioso. Además, ninguna de ellas conocía el objetivo final del material ni el interés kinésico-gestual de los vídeos para mi trabajo posterior. De este modo, el análisis resulta más auténtico y con menos interferencias derivadas de la paradoja del observador (LABOV, 1972a, p. 209). Incluso así, y es algo que se puede apreciar, al comienzo de las grabaciones de los vídeos, ellas están más rígidas 
y con la gestualidad más artificial de lo normal (en un caso por exceso y en el otro por defecto). En los primeros segundos se ve que ambas están pendientes de la cámara, pero un poco después pasan a comportarse con bastante naturalidad. Es interesante destacar que en las narraciones analizadas la función emotiva del lenguaje (JAKOBSON, 1981, p. 33-34) es la predominante y eso provoca que las dos hablantes estén más atentas al hilo de sus discursos que a lo que transmiten con sus gestos y posturas.

Ellas cuentan dos historias que podemos clasificar como narrativas personales orales (LABOV, 1972b, p. 354-396) y con una clara vocación humorística. En ambos casos se puede observar que la gestualidad juega un papel determinante.

Los vídeos de las narraciones que forman parte del corpus del trabajo de este artículo están disponibles para el público en los siguientes links:

1. Gallego: https://vimeo.com/107201428

2. Portugués de Brasil: https://vimeo.com/124373960

Además, para facilitar el seguimiento de los vídeos por parte de los lectores he incluido una transcripción verbal de las dos narraciones que se encuentra en el apéndice, al final del artículo.

\section{Análisis de las metáforas kinésicas}

Para poder analizar las metáforas kinésicas presentes en estas narraciones, aprovecho las grabaciones en vídeo que realicé, de las que extraigo los fotogramas de algunos momentos gestuales y kinemas que me parecen más interesantes por su mayor representatividad. Además, siguiendo la dinámica de trabajos anteriores (RIVAS, 2008, 2015), a partir de esas imágenes comento las implicaciones que los movimientos provocan en el discurso.

En primer lugar, voy a analizar algunas metáforas en la narración de la hablante de gallego. En esta narración me gustaría destacar que se trata de una historia de carácter humorístico, en la que la narradora va creando expectativas hasta alcanzar el clímax en los momentos finales del relato. 
FIGURA 1 - despois eles seguían (0’32”).

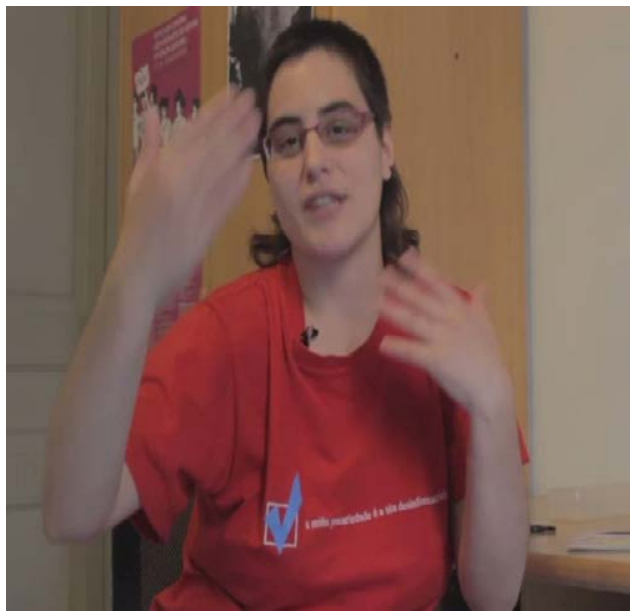

Fonte: https://vimeo.com/107201428

$\mathrm{Si}$ atendemos únicamente al movimiento de las manos, la narradora parece tímida al comienzo de su narración, sin utilizar un espacio gestual demasiado amplio, con los brazos y las manos situados cerca del tronco. Pero conviene recordar que no todos los gestos se producen con las manos y advertir que, a pesar de que los movimientos de las manos son muy visibles, tampoco son siempre los gestos más determinantes. Por eso resultan más interesantes los primeros movimientos que se producen lejos del cuerpo. En la figura 1 se observa cómo su mano derecha, con la palma abierta y plana (en forma de plancha) a la altura de la cara se prepara para realizar un movimiento semicircular. Con el brazo ligeramente erguido la mano avanza separándose del tronco, aproximadamente veinte centímetros, y después va descendiendo, continuando hasta pararse bruscamente a la altura del. Al mismo tiempo, el brazo izquierdo permanece apoyado en el reposabrazos de la silla y sólo los dedos de la mano izquierda se van abriendo y alejando del cuerpo al mismo tiempo que la otra mano marca el punto temporal coincidiendo con la pronunciación de la palabra "despois".

En este primer gesto la metáfora que se trasluce tiene carácter temporal: la metáfora "el tiempo es espacio" es una de las metáforas más utilizadas y asumida comúnmente en la cultura occidental, relacionada con la concepción lineal del tiempo y del discurso. De este modo se observa que para la narradora el ayer queda atrás, mientras que el mañana está hacia adelante. 
FIGURA 2 - despois eles seguían (0’32”-0’33”).

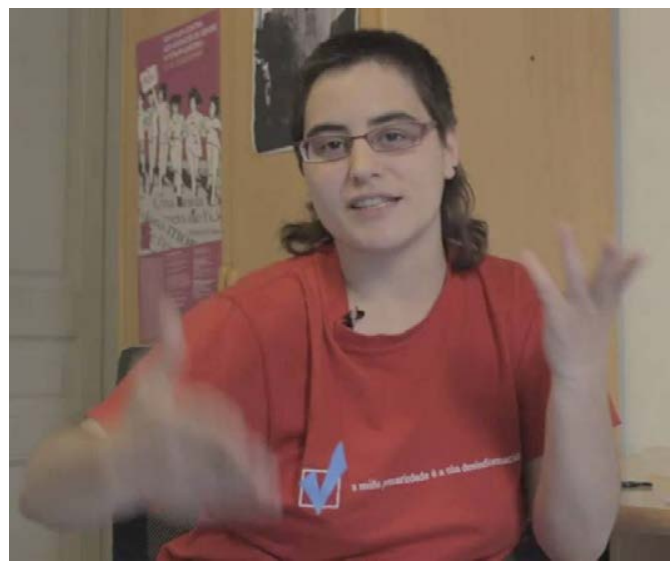

Fonte: https://vimeo.com/107201428

Como se puede apreciar en las figuras 1 y 2 las manos se mueven de forma independiente, pues en este caso la mirada continúa fija en la cámara. Cada mano es un ilustrador. Existe un espacio determinado en el que se realizan los movimientos. En este caso la mano izquierda representa un hito, un objeto que marca el espacio aéreo, transformándolo en algo físico y metaforizando así la línea temporal (dibujando una forma para algo que no la tiene).

FIGURA 3 - despois eles seguían (0’33”).

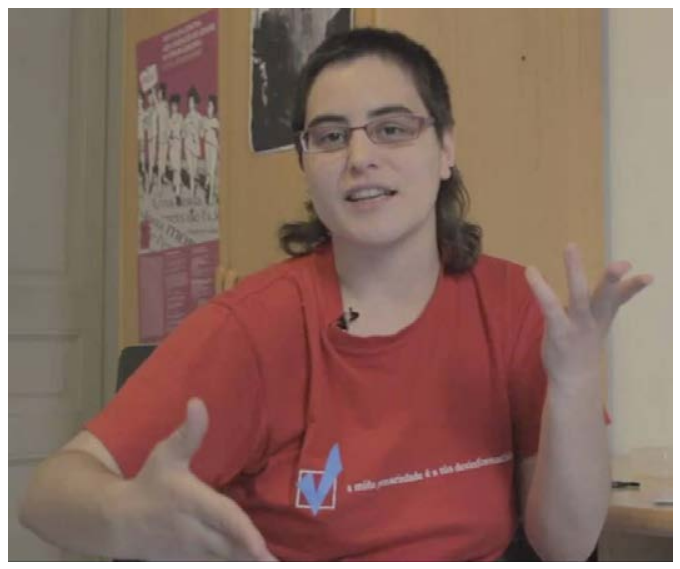

Fonte: https://vimeo.com/107201428 
En la figura 3, que representa el final de la metáfora kinésica, se observa que la mano derecha se mantiene fija, firme en el mismo espacio, mientras su mano izquierda termina su movimiento. Este hecho ayuda a que el espectador imagine el punto temporal futuro y, al mismo tiempo, enriquece el discurso del relato.

Como explica en su trabajo sobre las metáforas orientacionales López Olea (2012, p. 44), "por nuestra experiencia al caminar en el espacio en una línea recta, un camino, donde dejamos atrás lugares que conocemos y vamos hacia lugares nuevos, conceptualizamos el tiempo en términos del espacio de esa manera". Así, la mayor parte de las culturas y lenguas analizadas, consideran que el pasado queda atrás y el futuro es adelante. Los tres casos excepcionales descubiertos hasta el momento en los que el futuro es atrás y el pasado es adelante son el de los aymaras, los qom y los malgaches (RADDEN, 2003, p. 1-14).

FIGURA 4 - ciclo (0’44" - 0’45”).

FIGURA 5 - ciclo (0’45").

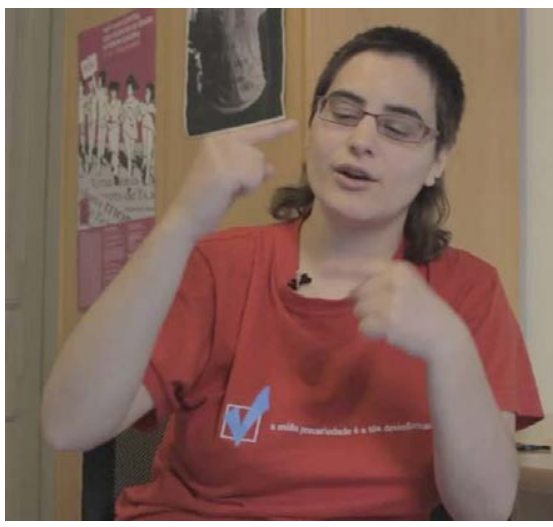

Fonte: https://vimeo.com/107201428

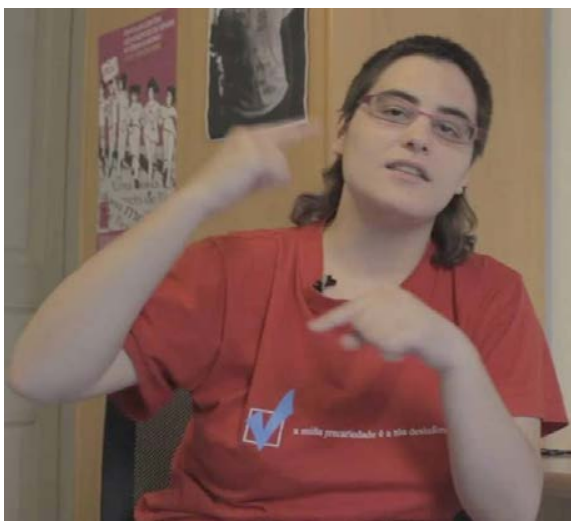

Fonte: https://vimeo.com/107201428

En las figuras 4 y 5 aparece otra metáfora muy común que coincide con la pronunciación de la palabra "ciclo" y refuerza su significado. El ciclo se representa como una rueda. Se trata de otra metáfora gestual para indicar la repetición, demostrando a su vez la concepción espacial para metaforizar un concepto tan abstracto como el tiempo. Como afirmaron Ahrens y Huang (2002), el paso del tiempo implica siempre un movimiento. Seguramente debido a eso el movimiento circular de las manos no se detiene, indicando así la repetición. Es curioso porque esta representación se contrapone con la visión lineal del tiempo que comenté 
anteriormente.

Siguiendo con la narración del relato, hay un ejemplo que me parece especialmente significativo para ilustrar el comportamiento de la kinésica en relación con el discurso verbal. En esta narración, como en muchos otros casos, existen algunos gestos no planificados por la narradora que muestran reacciones personales al propio discurso que ella misma está elaborando.

En la figura 6 aparece la narradora con la mirada, la cabeza e incluso el cuerpo orientado hacia abajo, cabeceando de forma negativa. Este movimiento se produce como una reacción al discurso oral que lo precedía: "É imposíbel que no século $X X$, a [no sé...] a principios do século XXI, haxa xente que poida ter, no mundo occidental, esta enfermidade. Non o poido crer. Non o poido crer" (GALICISCH LEKTOR, 2015a). A respecto de las metáforas orientacionales, el trabajo de López Olea (2012, p. 75-83) ya demostró que lo bueno es arriba y lo malo es abajo, indicando que no tendría que ser así necesariamente en todas las culturas.

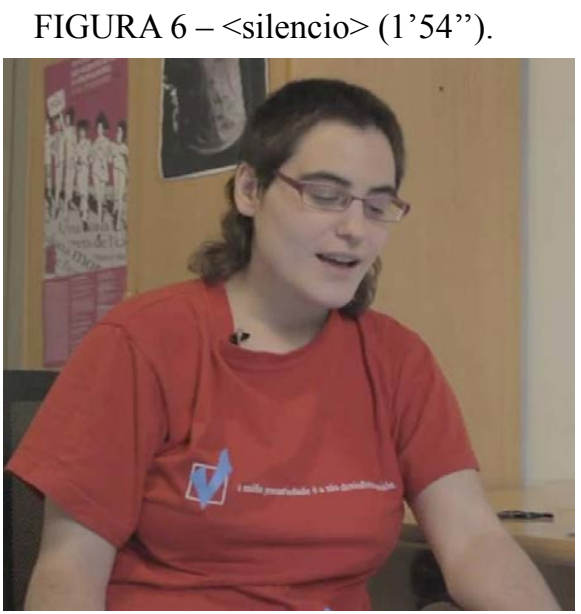

Fonte: https://vimeo.com/107201428

Probablemente debido a la influencia de la tradición católico-cristiana en la cultura occidental los espacios mentales de las historias se reparten así: arriba están las cosas buenas (el Cielo); abajo, las malas (el Infierno). Esto hace que los gestos orientados hacia la parte superior — del mismo modo que la simbología y significados que crean - sean positivos; sin embargo, los gestos direccionados hacia abajo suelen tener una connotación negativa. En este caso la narradora, 
encarnando el papel de médico, utiliza inconscientemente ese espacio inferior para reforzar la negación con la cabeza y demostrar la incredulidad y desconformidad del médico con la enfermedad que había diagnosticado y que se revela como una parte esencial para mantener la tensión de la historia y para la preparación del gag final. La metáfora espacial refuerza aquí la reacción negativa del personaje del médico, contribuyendo a dotar de un carácter humorístico a toda la narración.

Los dos ejemplos que presento en las figuras 7 y 8 son paradigmáticos para comprender la función creadora de espacios que pueden cumplir las metáforas. En el primer caso (figura 7) se produce un breve silencio involuntario y parece que la narradora no sabe cómo continuar el discurso. Lo que hace es subir la cabeza, con los ojos abiertos, centrando la mirada en un punto fijo mientras parece que busca las palabras para poder continuar la narración. Ese espacio metafórico que crea se puede entender como un espacio diferente del espacio principal, en el que están los personajes de la historia que nos está contando. En ambas interrupciones del gesto existe una metáfora de búsqueda: la dirección de la mirada delimita un plano distinto, que no pertenece a la historia, sino a la realidad y al momento de la enunciación. Entonces aparecen dos planos: el primero, que se corresponde con el espacio en el que se mueven los personajes de la narración; y el segundo, donde sólo puede entrar la narradora para buscar cosas que necesita para continuar con la historia. En la mayor parte de las ocasiones se trata de pequeños "viajes gestuales" que realiza la narradora a ese plano propio, volviendo inmediatamente al otro plano para continuar con la historia de los personajes.

FIGURA 7 - vale (2'25”).

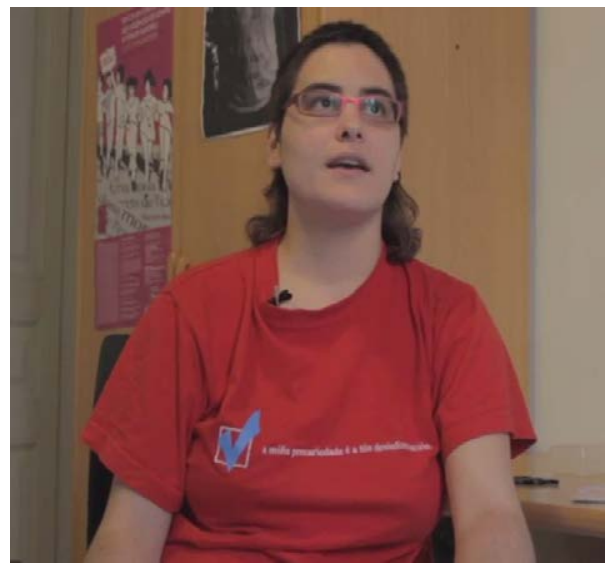

Fonte: https://vimeo.com/107201428 
FIGURA 8 - nunca bebedes algo de zumo? (2’39”).

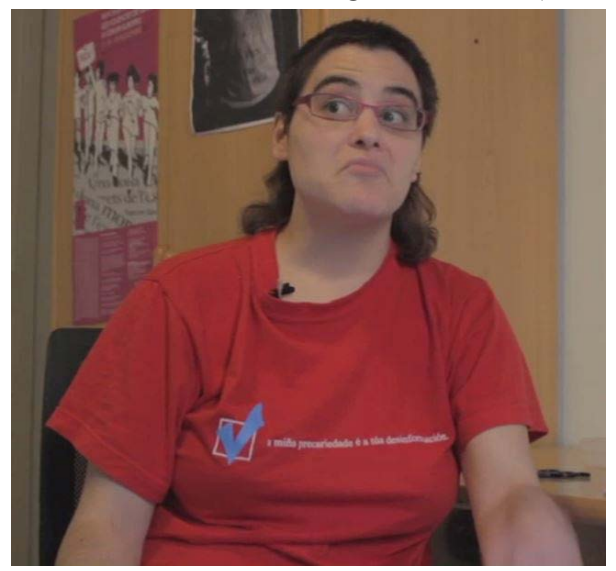

Fonte: https://vimeo.com/107201428

El gesto de la figura 8 tiene lugar inmediatamente después de la pregunta del doctor: "-E nunca bebedes algo de zumo?". Al pronunciar esas palabras la mirada de la narradora se dirige hacia arriba y a su derecha en un eje diagonal, la boca se cierra con la comisura de los labios hacia abajo y las cejas se arquean de un modo exagerado. Se trata de un exteriorizador con el que se muestra la reacción de un personaje frente a la realidad que está viviendo (POYATOS, 1994a, p. 206). La narradora imita con su cara la expresión que pondría uno de los protagonistas en ese momento.

Pero entre estos dos ejemplos de metáforas gestuales existe una diferencia: la intención. Mientras que en la figura 7 parece que la narradora pierde el hilo del discurso, en la 8 se trata de un mecanismo para marcar un cambio de roles, es decir, indica el momento en que la narradora deja de representar al médico y pasa a asumir la representación de uno de los otros dos personajes de la historia.

A continuación voy a analizar algunos gestos en una narración de portugués de Brasil, no para compararlos con la narración gallega, sino con el objetivo de completar la explicación sobre algunos procedimientos de creación de las metáforas kinésicas. 
FIGURA $9-<$ silencio $>$ (0’33”).

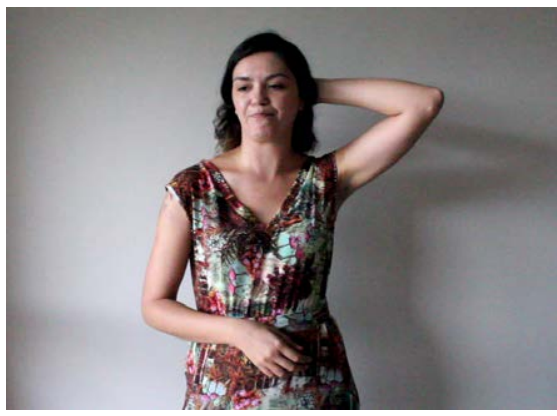

Fonte: https://vimeo.com/124373960
FIGURA 10 - E a Lidiane (0’35”).

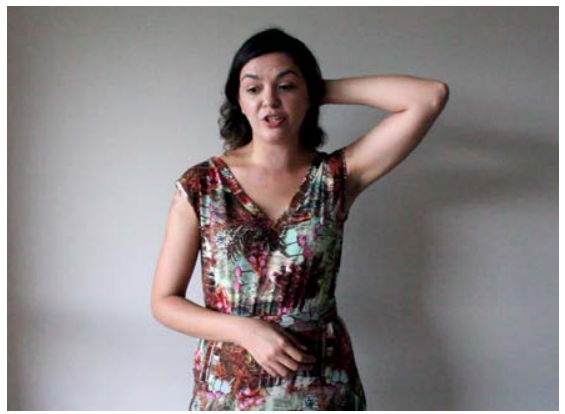

Fonte: https://vimeo.com/124373960

Las figuras 9 y 10 representan una metáfora de la búsqueda en la que, como comenté con anterioridad, la mirada de la narradora se aparta de la cámara, evadiéndose de la historia durante unas fracciones de segundo, esperando que esta evasión le ayude a recordar algún detalle de la narración.

En este caso se puede observar que el "viaje gestual" de la narradora a su plano privado empieza durante un silencio y continúa durante cuatro segundos (0’33”0'37"), estando prácticamente ausente de la historia, incluso cuando vuelve a retomar el discurso verbal, como se ve en la figura 10.

Quizá ella trate de buscar en estos primeros compases de la narración estrategias y recursos que le puedan servir más adelante, utilizando ese momento de evasión para planificar la historia que va a contar, anticipándose a los acontecimientos y evitando posibles problemas narrativos.

Durante el silencio (figura 9), aprovecha para tragar saliva y respirar. Después, cuando ya comienza con el discurso. Es interesante destacar que la mano y el brazo izquierdo acompañan este proceso de búsqueda, colocándose detrás de la nuca, tocándose el pelo. Se trata de un autoadaptador (POYATOS, 1994a, p. 211) en el que una parte del cuerpo entra en contacto con otra, con un movimiento que le sirve para ocupar la mente pensando en una actividad diferente, favoreciendo su concentración en el discurso.

En la siguiente imagen (figura 11) se ve otro autoadaptador acompañado de una detención del gesto en la que la mano derecha de la narradora agarra rápidamente los dedos de la mano izquierda, antes de soltarla para rascarse la espalda detrás de su hombro derecho. Al mismo tiempo, y mientras continúa contando la historia, su mirada desaparece del foco en uno de esos frecuentes viajes gestuales de búsqueda 
que comenté en un ejemplo anterior. En este caso concreto lo curioso es que la mirada permanece ausente durante el siguiente fragmento: "e... bom, naquele dia eu e a minha amiga Livia, a gente tinha ido no estádio, pedir autógrafo dum jogador de futebol" (GALICISCH LEKTOR, 2015b). Se trata de una metáfora de búsqueda de gran duración, prácticamente de nueve segundos, desde 1'37" hasta 1'45". Durante este tiempo ella parece ausente del momento en el que está contando la historia, absolutamente concentrada en el otro plano —el de la narradora-, quizá recordando las sensaciones vividas en aquella situación en la que estuvo implicada personalmente y que está recreando con su narración.

FIGURA $11-$ e... (1'38").

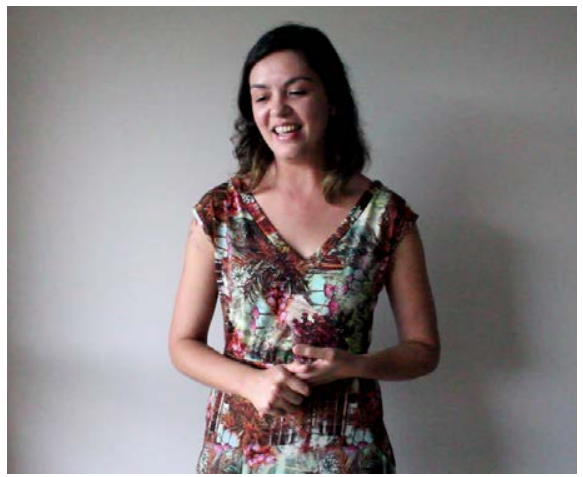

Fonte: https://vimeo.com/124373960
FIGURA 12 - o objetivo dela (2’36”).

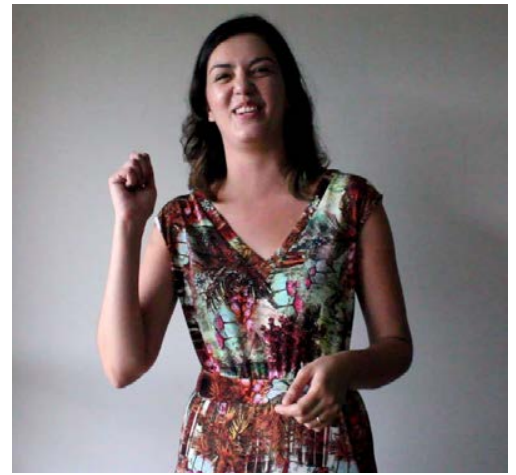

Fonte: https://vimeo.com/124373960

Sea debido a los nervios sea por cualquier otro motivo, parece que la narradora brasileña es consciente de que está gesticulando “demasiado". Quizá por eso intenta agarrarse las manos en varias ocasiones de su relato (figura 11).

Relacionado con el tema de la gesticulación, es muy interesante la percepción que tienen muchas personas sobre la cantidad de los gestos. Es frecuente creer que en algunas culturas existen más gestos, como por ejemplo que los italianos "hacen más gestos" que en los países nórdicos. Probablemente ese prejuicio tan extendido se refiera a la calidad de los gestos, es decir, por ejemplo a la amplitud y separación del tronco de los movimientos de los brazos o a la velocidad de las manos. Es cierto que existen emblemas y gestos icónicos propios de cada cultura, pero no lo es menos que en otras culturas existe otro tipo de gestualidad. Es posible que se trate de gestos más sutiles y con menor proyección hacia el exterior, más cercanos del tronco o, por ejemplo, con mayor gestualidad y expresividad facial, quizá no tanto corporal. 
En la figura 12 identifiqué otro proceso de metaforización kinésica: se trata de la representación del concepto abstracto "objetivo". Con la mano derecha cerrada y doblando el brazo hacia arriba, levanta el puño, como si estuviese celebrando una victoria deportiva o levantando un trofeo. Es importante recordar aquí lo visto anteriormente sobre la metáfora orientacional "arriba es bueno, abajo es malo". En este caso, la representación metafórica creada por la narradora parodia la consecución del objetivo, el triunfo de la amiga, contribuyendo a la realización de un recurso humorístico que enriquece la versión cómica de la narración y provocando incluso la propia risa.

FIGURA 13 - chamou (5’03”)

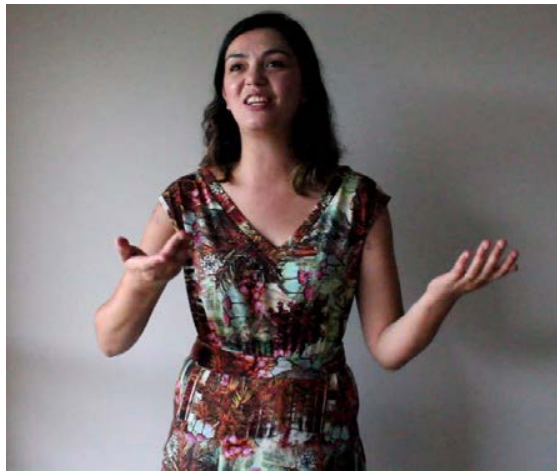

Fonte: https://vimeo.com/124373960
FIGURA 14 - chamou (5’03”)

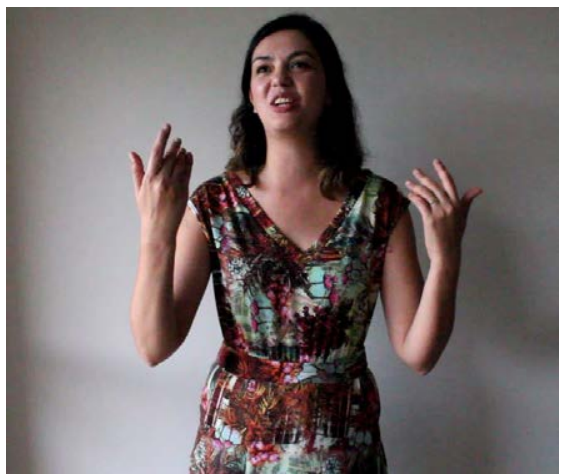

Fonte: https://vimeo.com/124373960

Finalmente, los últimos kinemas que elegí para mi análisis en este artículo están relacionados con la metaforización y representación visual del verbo "llamar".

Al mismo tiempo que la narradora pronuncia "e alguém chamou a gente" las dos manos (extendidas hacia adelante y con las palmas abiertas hacia arriba) se mueven acompasadamente hacia el tronco a la altura de los hombros, como se puede apreciar en las figuras 13 y 14. El movimiento es rápido y coincide exactamente con el momento de expresión verbal, puntualizando la palabra "chamou". Se trata de la metaforización del concepto de llamada, queriendo dibujar con las manos toda la carga semántica de la respuesta afirmativa de la llamada, es decir, la llegada. 


\section{Conclusiones}

Las personas son dinámicas y se expresan mediante gestos. Por eso el gesto va más rápido que la palabra y la razón. Después de este pequeño análisis de estas dos narraciones, se puede afirmar que, efectivamente, el gesto es más representativo y transmite las metáforas orientacionales una manera más directa que la palabra.

Como ya había constatado con anterioridad (RIVAS, 2015) al analizar el comportamiento kinésico de un narrador, puedo concluir que la producción y la transmisión de pensamientos no es solamente verbal, sino que también intervienen otros aspectos y comportamientos no verbales que provocan la risa, las dobles interpretaciones y la complicidad con los oyentes en la aparición del humor. Aunque las dos narradoras tienen marcas de estilo y diferentes particularidades en sus narraciones, tras la observación y el análisis llevado a cabo, estas son las conclusiones más destacadas:

1. La comunicación no verbal es un elemento muy importante de expresión, especialmente en lo que respecta a la creación de metáforas en las narrativas orales de cualquier comunidad de habla.

2. El sistema kinésico que complementa el discurso oral cambia entre diferentes lenguas y culturas, pero tiene unos padrones y normas comunes y suele dibujar emociones que se distribuyen en el espacio. Por ejemplo: arriba y ojos abiertos indican una actitud positiva, mientras que abajo y los ojos cerrados se refieren a algo negativo.

3. Los lapsus, dudas y repeticiones en el discurso verbal espontáneo intervienen directamente en la aparición de más elementos de la comunicación no verbal, haciendo que la frecuencia en la aparición de metáforas kinésicas sea mayor.

4. La gestualización de metáforas conceptuales como "el pasar del tiempo es movimiento" demuestra que el discurso es lineal y, en la cultura occidental, el tiempo avanza hacia adelante.

5. Los procesos de metaforización kinésica son muy enriquecedores dentro de las narraciones y, debido a eso, podemos afirmar que las oportunidades de representación metafórica se multiplican si se observa con atención el componente kinésico de una narración oral.

6. Cuando tienen una laguna mental en la narración de la historia, las narradoras desvían su mirada hacia un lateral o hacia arriba, para buscar las palabras apropiadas y continuar con el hilo conductor de la historia. 
7. Los marcadores espaciales metafóricos (especialmente aquellos movimientos que cuentan con la intervención de los ojos y de la cabeza) son muy comunes en las narrativas personales con el objetivo de acompañar el discurso verbal y también dibujar espacios metafóricos que completan el significado de la historia.

8. El análisis de la comunicación no verbal es de vital importancia para entender el funcionamiento de las metáforas en una narración oral, porque contribuye a crear nuevos significados que no están presentes en el discurso verbal y a reforzar otros, creando un entramado en el que se ensamblan perfectamente los componentes verbales y no verbales de la narración.

\title{
A metáfora da procura: análise da metaforização cinésica em duas narrativas orais em galego e português
}

\begin{abstract}
Resumo
Admite-se, partindo das ideias de Hall $(1959,1968)$, que $60 \%$ da comunicação pessoal é absolutamente não verbal, sendo considerado muito mais importante o que transmitimos com os nossos gestos do que aquilo que expressamos verbalmente. O corpus de estudo para este trabalho está conformado por duas narrações orais de falantes nativas de galego e português do Brasil. Neste artigo, analisarei a intervenção da comunicação não verbal nos procedimentos de metaforização cinésica para transmitir e representar metáforas nos relatos orais. A metodologia de trabalho está baseada nas propostas de análise de comunicação não verbal formuladas por Birdwhistell (1952, 1970), Poyatos (1994a, 1994b), Bouvet (2001) e Galhano Rodrigues (2007). Com a análise pode-se observar a alta capacidade metafórica dos procedimentos cinésicos.
\end{abstract}

Palavras-chave: Metaforização. Cinésica. Não verbal. Oralidade. Procura. 


\section{Referencias}

AHRENS, Kathleen; HUANG, Chu-Ren. Time passing is motion. In: Language and Linguistics, v. 3, n. 3, 491-519, 2002.

BIRDWHISTELL, Ray L. Introduction to Kinesics: An Annotation System for Analysis of Body Motion and Gesture. Washington, DC: Department of State, Foreign Service Institute, 1952. 75p.

BIRDWHISTELL, Ray L. Kinesics and Context: Essays on Body Motion Communication. Philadelphia: University of Pennsylvania Press, 1970. 338p.

BOUVET, Danielle. La dimension corporelle de la parole. Les marques posturomimo-gestuelles de la parole, leurs aspects métonymiques et métaphoriques, et leur rôle au cours d'un récit. Paris: Peeters, 2001. 155p.

CIENKI, Alan; MÜLLER, Cornelia. Metaphor and Gesture. Amsterdam/ Philadelphia: John Benjamins Publishing Company, 2008. 306p.

DURANTI, Alessandro. Antropología lingüística. Madrid: Cambridge University Press, 2000 [1997]. 525p.

GALHANO RODRIGUES, Isabel M. O Corpo e a fala. Sinais verbais e nãoverbais na interacção face a face. Lisboa: Fundação Calouste Gulbenkian. Fundação para a Ciência e a Tecnologia, 2007. 827p.

GALICISCH LEKTOR. 1. Raquel (Galego). Grabación en vídeo. 2015a. Disponible en: $<$ https://vimeo.com/107201428>. Acceso: 31 de marzo de 2016.

GALICISCH LEKTOR. 7. Simone (Portugués de Brasil). Grabación en vídeo. 2015b. Disponible en: <https://vimeo.com/124373960>. Acceso: 31 de marzo de 2016.

HALL, Edward T. The Silent Language. Nueva York: Doubleday \& Co., 1959. 240p.

HALL, Edward T. Proxémica. In: WINKIN, Yves (Org.) La nueva comunicación. 4. a ed. Barcelona: Kairós, 2005 [1968]. 198-229.

JAKOBSON, Roman. Lingüística y poética. Estudio preliminar de Francisco Abad (Trad. Ana M. ${ }^{a}$ Gutiérrez-Cabello). Madrid: Cátedra, 1981. 75p.

LABOV, William. Sociolingustic Patterns. Philadelphia: University of Pennsylvania Press, 1972a. 344p.

LABOV, William. Language in the inner city. Philadelphia: University of Pennsylvania Press, 1972b. 412p. 
LÓPEZ OLEA, Moisés. Gesto y metáfora: la interrelación entre los espacios mentales de las metáforas orientacionales arriba-abajo y los espacios físicos de la expresión gestual. Querétaro: Universidad Autónoma de Querétaro, 2012. 101p. Disponible en: <http://ri.uaq.mx/handle/123456789/1639>. Acceso: 31 de marzo de 2016.

POYATOS, Fernando. La comunicación no verbal. I. Cultura, lenguaje y conversación. Madrid: Istmo, 1994a. 296p.

POYATOS, Fernando. La comunicación no verbal. II. Paralenguaje, kinésica e interacción. Madrid: Istmo, 1994b. 348p.

RADDEN, Günter. The Metaphor TIME AS SPACE across Languages. In: BAUMGARTEN, Nicole; BÖTTGER, Claudia; MOTZ, Markus; PROBST, Julia (Eds.). Übersetzen, Interkulturelle Kommunikation, Spracherwerb und Sprach-vermittlung - das Leben mit mehreren Sprachen. Festschrift für Juliane House zum 60. Geburtstag. Zeitschrift für Interkulturellen Fremdsprachenunterricht, 8，2003. 1-14. Disponible en: <https://zif.spz.tudarmstadt.de/jg-08-2-3/beitrag/Radden1.htm>. Acceso: 31 de marzo de 2016.

RIVAS, Aitor. Introdución á comunicación non verbal. Panorama de investigación. In: FERNÁNDEZ REI, Elisa; REGUEIRA, Xosé Luís (Eds.). Perspectivas sobre a oralidade. Santiago de Compostela: Instituto da Lingua Galega / Consello da Cultura Galega, 2008. 141-167.

RIVAS, Aitor. "No ximnasio": análise quinésica do relato dun contacontos. LINCOM Studies in Communication 11. München: Lincom Europe, 2015. 148p. TORRALBA, F. Rostres del silenci. Lleida: Pagès Editors, 2006. 167p.

\section{Apéndice con las transcripciones de los textos}

\section{Texto en gallego}

Bueno, vouche contar unha historia que... lle aconteceu a unha xente que coñecín cando vivía en Compostela. O caso é que, bueno, é unha historia de... de dous rapaces, que eles vivían de noite, non? Un... traballaban nunha discoteca... e entonces o que facían era... [pola ma... o que era]... pola noite levantábanse a iso das oito ou nove da noite, almorzaban, e... [sa] e... arreglábanse para ir a traballar de noite á discoteca, estaban na na discoteca hasta as cinco da mañá, despois eles 
seguían de marcha hasta iso das nove ou dez da mañá, e... ían a un bar a comer o seu bocata de zorza i dispós volvían para a casa i volvían a dormir, e así este ciclo repetíase día tras día todos os días da semana e... menos o... luns, que o luns para o martes descansaban, non? O caso é que... un día nesta vida nocturna [un día] un dos rapaces díxolle ao seu compañeiro: - Ei, que, noto como que a miña mandíbula se move. Parece que me caen os dentes. Non sei que me pasa... no? Teño esa sensación de que caen os dentes. E o seu compañeiro lle dixo: - Jo, eu tamén teño [esta] esta mesma sensación. E téñoa desde hai unha semana, máis ou menos. Ti? - Eu tamén. Desde hai unha semana. Non sei que pasa. O caso é que decidiron ir ao médico, no? porque estaban así un pouco inquietos. E o médico, bueno, flipou un poquiño porque, cando chegou, cando chegaron e lle contaron o que lle estaba pasando e lle fixo, pois unha revisión i tal, o médico díxolle: - Nunca, nos meus vinte anos de... de traballo como médico vin esta enfermidade. Pensei que xa estaba erradicada. É imposíbel que no século XX, a [no sé...] a principios do século XXI, haxa xente que poida ter, no mundo occidental, esta enfermidade. Non o poido crer. Non o poido crer. E a verdade é que, claro, estas palabras do médico... puxeron un pouco nerviosos a estes rapaces porque era como... - Que pasa? Que pasa? Temos unha enfermidade rara. Que...? Que pasa? Que pasa? E o médico empezoulle a preguntar: - Bueno, a ver, vós que tipo de vida levades? - Bueno, non, é que nós é que traballamos de noite. Traballamos nunha discoteca. - Vale: Que bebedes? - Bueno... bebemos bastante cocacola con ron e, claro, cubatas i tal. - Vale: i que comedes? - Bueno, comemos bastante... bastante... carne, xeralmente un dos nosos platos favoritos é bocata, un bocadillo con zorza. - I nunca bebedes algo de zumo? - No, a verdade é que no, só bebemos... claro bebemos moito cubata, a verdade é que zumos non é... non é a nosa bebida favorita. - Pois mirade, vós o que tedes é escorbuto, principios de escorbuto, que é unha... é esa enfermidade que matou os mariñeiros [da, do...] dos barcos de Colón cando viaxaba a América ou mataba tamén os presos, nas cadeas, cando estaban e... presos, pois por exemplo na época de Franco, na ditadura. Pero o increíble é que hoxe en día, no ano dous mil tres vós teñades os principios de escorbuto... Só con tomarvos un cubata con zumo de... con kas de laranxa teriades o suficiente zumo e suficientes vitaminas como para poder... para que o voso corpo non teñades esta enfermidade. E así foi como estes dous rapaces pasaron de beber cubatas con cocacola... a beber cubatas con fanta limón. 


\section{Texto en portugués de Brasil}

Bom, quando eu morei em Lyon, né? eu tinha duas grandes amigas brasileiras que eu fiz lá, na verdade é assim, eu tinha três grandes amigas brasileiras.. e uma grande amiga polonesa. A polonesa e a primeira brasileira eu encontrei no tempo em que eu fazia o curso de línguas.. e as outras duas brasileiras eu encontrei por acaso, assim, na rua sabe? em conversas.. e a gente ah, você é brasileira também? enfim, e a gente fez amizade. E essas duas meninas brasileiras, essas outras duas, uma era de Campinas e a outra do Rio. A Livía e a Lidiane. E a Lidiane, naquele tempo, ela era apaixonada por um espanhol. (risas) Ela era louca apaixonada por um menino espanhol que elas tinham conhecido na Aliança Francesa de Lyon e.. o menino tava fazendo graduação lá na universidade de Lyon. A Lidiane foi pra lá com passaporte português, ela foi pra trabalhar, então ela parou de fazer o curso depois de um tempo, ela não encontrava tanto esse rapaz, mas continuou com o rapaz na cabeça tentou esquecer, saiu com outros carinhas, não deu certo, ela gostava mesmo era do tal do espanhol. Ai quando um dia a Lidiane decide que ela vai fazer uma festa.. Ela vai dar uma festa porque ela quer encontrar... quer tem um pretexto para encontrar o espanhol e tentar seduzi-lo. (risas) E ela era muito ardilosa, ela decide então fazer essa festa, ela manda uma mensagem, um sms pra todos os amigos convidando pra festa de despedida dela. Ela inventa que ela vai embora, ela convence todo mundo no trabalho a fazer a festa de despedida dela, sendo que ela não vai embora, e convida todos os amigos e o espanhol. E... bom, naquele dia eu e a minha amiga Lívia, a gente tinha ido no estádio, pedir autógrafo dum jogador de futebol, foi um... toda uma outra história, enfim... e a gente chega lá na festa meio esbaforida, com umas coisas de Carrefour assim, umas batatas fritas, um qualquer coisa ali pra servir na festa, né? E começa a bater papo... bom... na festa a gente acabou fazendo amizade com um grupo de franceses. Quando a gente é estrangeiro num país, muitas vezes a gente faz amizade com os estrangeiros, né? E era o nosso caso, então, é... a gente não tinha muitos amigos assim na França, né? Mas naquele dia, acho que a gente bebeu um pouco além da conta, a gente bateu papo com todo mundo e cantou, e naquele dia me ensinaram o hino da internacional comunista em francês (risas) no meio da festa, pro cês terem noção do nível da festa. A festa foi muito boa, foi excelente, é... e a minha, nossa amiga né, conseguiu ficar lá com o espanhol (risas) o objetivo dela (risas), ela conseguiu alcançar. É, num sei porque que eu tô contando isso, mas enfim... 
(risas) a gente, a gente ficou lá cantando, batendo papo até umas cinco da manhã. Às cinco da manhã a gente se deu conta de que eram cinco da manhã e que a gente precisava viajar, a gente tinha marcado uma viagem, é... pro sul da França, eu não conhecia o sul da França, essa minha amiga Lívia, ela já tinha morado no sul da França e ela falou vamo, a gente passeia tudo e eu vou apresentar pra você uma família com quem eu trabalhei como au pair, que cê vai adorar, eles tão precisando de alguém, você quer ir embora de Lyon, vai ser ótimo. Eu só sei que a gente ficou, foi uma maratona muito louca porque a gente foi pedir autógrafo, depois foi pra festa, fez amizade, cinco da manhã, a gente, com os... as mesmas pessoas que ensinaram o hino pra gente, a gente foi até a estação de trem, na estação de trem a gente se despediu da galera, pegou o trem, foi dormindo no trem até chegar em Montpellier, chegamos em Montpellier demos duas voltas no centro e a Lívia me chamou pra ir na casa de uma amiga dela, ela tinha uma grande amiga lá que ela encontrou também nos bares, nas festas e... essa amiga falou, a não vem aqui em casa, a gente toma um café, a gente tava sem dormir, deu uma descansada, a gente dormiu lá uma horinha, no que a gente acordou ela falou assim eu vou chamar vocês pra uma outra festa, vai ter uma festa aqui na cidade (hhhh) e... a gente não sabia do que se trata, do que se tratava mas a gente sabia que era uma festa na rua e ela falou, não, vamo lá, vai ser ótimo, eu vou levar alguma coisa pra comer, vocês não precisam levar nada, vocês tão chegando hoje. Eu sei que a gente desceu e eu fiquei encantada, foi, eu acho que uma das coisas mais lindas que eu vi na França, ne? Primeiro que eu fiquei encantada com a cidade de Montpellier, eu tinha acabado de sair de Lyon ainda tava frio em Lyon, a gente de casaco e Montpellier um sol lindo, um tempo maravilhoso e era a fête des voizins, a festa dos vizinhos na França. Então a gente saiu na rua eram grandes mesas nas praças, as pessoas todas comendo juntas, a gente foi pra uma grande praça pública, tinha um grupo de senhoras dançando a hula, alguma coisa assim sabe? É, sabe essas coisas meio kitsch mas muito divertidas e gostosas, e alguém chamou a gente pra sentar junto, passou o chapéu pra pagar o vinho, a gente tomou lá o vinho, comeu uma comida diferente. Foi tão mágico aquele dia, que parecia que assim, que eu já tava dormindo né? Parecia que era isso. Bom, enfim, foi um fim de semana maluco. A história continua, mas a gente para por aqui (risas)...

Recebido em 10/04/2016.

Aceito em 05/07/2016. 